\title{
Early-Life Exposure to Polycyclic Aromatic Hydrocarbons and ADHD Behavior Problems
}

\author{
Frederica P. Perera ${ }^{1,2 *}$, Hsin-wen Chang ${ }^{2,3}$, Deliang Tang ${ }^{1,2}$, Emily L. Roen ${ }^{1,2}$, Julie Herbstman ${ }^{1,2}$, \\ Amy Margolis ${ }^{2,4}$, Tzu-Jung Huang ${ }^{2,3}$, Rachel L. Miller ${ }^{1,2,5,6}$, Shuang Wang ${ }^{2,3}$, Virginia Rauh ${ }^{2,7}$
}

1 Department of Environmental Health Sciences, Mailman School of Public Health, Columbia University, New York, New York, United States of America, 2 Columbia Center for Children's Environmental Health, Columbia University, New York, New York, United States of America, 3 Department of Biostatistics, Mailman School of Public Health, Columbia University, New York, New York, United States of America, 4 Division of Child \& Adolescent Psychiatry and the Center for Developmental Neuropsychiatry, Department of Psychiatry, the New York State Psychiatric Institute and the College of Physicians and Surgeons, Columbia University, New York, New York, United States of America, 5 Division of Pulmonary, Allergy and Critical Care of Medicine, Department of Medicine, College of Physicians and Surgeons, Columbia University, New York, New York, United States of America, 6 Division of Pediatric Allergy and Immunology, Department of Pediatrics, College of Physicians and Surgeons, Columbia University, New York, New York, United States of America, 7 The Heilbrunn Department of Population and Family Health, Columbia University, New York, New York, United States of America

\begin{abstract}
Importance: Polycyclic aromatic hydrocarbons are widespread urban air pollutants from combustion of fossil fuel and other organic material shown previously to be neurotoxic.

Objective: In a prospective cohort study, we evaluated the relationship between Attention Deficit Hyperactivity Disorder behavior problems and prenatal polycyclic aromatic hydrocarbon exposure, adjusting for postnatal exposure.

Materials and Methods: Children of nonsmoking African-American and Dominican women in New York City were followed from in utero to 9 years. Prenatal polycyclic aromatic hydrocarbon exposure was estimated by levels of polycyclic aromatic hydrocarbon- DNA adducts in maternal and cord blood collected at delivery. Postnatal exposure was estimated by the concentration of urinary polycyclic aromatic hydrocarbon metabolites at ages 3 or 5 . Attention Deficit Hyperactivity Disorder behavior problems were assessed using the Child Behavior Checklist and the Conners Parent Rating Scale- Revised.

Results: High prenatal adduct exposure, measured by elevated maternal adducts was significantly associated with all Conners Parent Rating Scale-Revised subscales when the raw scores were analyzed continuously $(N=233)$. After dichotomizing at the threshold for moderately to markedly atypical symptoms, high maternal adducts were significantly associated with the Conners Parent Rating Scale-Revised DSM-IV Inattentive (OR $=5.06,95 \% \mathrm{Cl}[1.43,17.93])$ and DSM-IV Total $(\mathrm{OR}=3.37,95 \% \mathrm{Cl}[1.10,10.34])$ subscales. High maternal adducts were positivity associated with the DSM-oriented Attention Deficit/Hyperactivity Problems scale on the Child Behavior Checklist, albeit not significant. In the smaller sample with cord adducts, the associations between outcomes and high cord adduct exposure were not statistically significant $(\mathrm{N}=162)$.
\end{abstract}

Conclusion: The results suggest that exposure to polycyclic aromatic hydrocarbons encountered in New York City air may play a role in childhood Attention Deficit Hyperactivity Disorder behavior problems.

Citation: Perera FP, Chang H-w, Tang D, Roen EL, Herbstman J, et al. (2014) Early-Life Exposure to Polycyclic Aromatic Hydrocarbons and ADHD Behavior Problems. PLoS ONE 9(11): e111670. doi:10.1371/journal.pone.0111670

Editor: Robert L. Tanguay, Oregon State University, United States of America

Received June 5, 2014; Accepted October 6, 2014; Published November 5, 2014

Copyright: (c) 2014 Perera et al. This is an open-access article distributed under the terms of the Creative Commons Attribution License, which permits unrestricted use, distribution, and reproduction in any medium, provided the original author and source are credited.

Data Availability: The authors confirm that, for approved reasons, some access restrictions apply to the data underlying the findings. The data on which the manuscript is based are not freely available in the manuscript, supplemental files, or in a public repository, although a de-identified dataset is available upon request. Requests for data should be submitted to the corresponding author, Dr. Frederica Perera, fpp1@columbia.edu. The data are not freely available because they contain a significant number of data elements that are considered Protected Health Information (PHI) under HIPAA regulations. We will make the data available upon request as a Limited Data Set, under a standard HIPAA Data Use Agreement that will be reviewed and approved by our Columbia University Privacy Officer.

Funding: Funding was provided by the National Institute for Environmental Health Sciences (NIEHS) and the U.S. Environmental Protection Agency (US EPA) NIEHS/EPA P01ES09600/R82702701, NIEHS/EPA P01ES09600/RD832141, NIEHS/EPA P01ES09600/RD834509, NIEHS R01ES08977. This publication was also made possible in part by US EPA grants RD832096, the John \& Wendy Neu Family Foundation, the New York Community Trust, Trustees of the Blanchette Hooker Rockefeller Fund, and an anonymous foundation. Funding from all the institutions listed was used towards the design and conduct of the study; collection, management, analysis, and interpretation of the data; and the preparation, review, and approval of the manuscript. Its contents are solely the responsibility of the grantee and do not necessarily represent the official views of the US EPA. Further, US EPA does not endorse the purchase of any commercial products or services mentioned in the publication. Findings expressed in this paper are the opinions of the authors and do not necessarily reflect the official opinion of the Centers for Disease Control and Prevention.

Competing Interests: The authors have declared that no competing interests exist.

*Email: fpp1@columbia.edu 


\section{Introduction}

Polycyclic aromatic hydrocarbons $(\mathrm{PAH})$, such as benzo[a]pyrene $(\mathrm{B}[\mathrm{a}] \mathrm{P})$, are toxic air pollutants released during incomplete combustion of fossil fuel, tobacco, and other organic material [1]. They are also found in the diet. In New York City (NYG) and other urban areas, traffic and residential heating are major local sources. There is also some contribution from coal-burning sources in states upwind. Urban, minority populations in the U.S. often have disproportionate exposure to air pollution and are at greater risk for adverse health and developmental outcomes from this exposure [2-5]. All of the mothers in the Columbia Center for Children's Environmental Health (CCGEH) NYG cohort had detectable levels of $\mathrm{PAH}$ in prenatal personal air samples; $42 \%$ had detectable levels of $\mathrm{B}[\mathrm{a}] \mathrm{P}-\mathrm{DNA}$ adducts in maternal blood; and $46 \%$ had detectable levels of $\mathrm{B}[\mathrm{a}] \mathrm{P}-\mathrm{DNA}$ adducts in cord blood. $\mathrm{B}[\mathrm{a}] \mathrm{P}$ is considered a representative $\mathrm{PAH}$ and is highly correlated with other PAH class members [6]. PAH-DNA adducts reflect individual exposure to $\mathrm{PAH}$, integrating exposure over a 2 3 month period [7] and via different routes (primarily inhalation and ingestion). Adducts provide a biologic dosimeter as they not only reflect inter-individual differences in exposure and uptake of $\mathrm{PAH}$ but also in detoxification and DNA repair [8,9].

Because of the heightened susceptibility of the fetus and young child, exposures to PAH and other environmental pollutants during the prenatal and early postnatal stages are of particular concern [10-13]. During the fetal period and early childhood years, the brain is rapidly developing and vulnerable to neurotoxic insults that may manifest as adverse outcomes in childhood and adulthood [14,15]. Laboratory studies of PAH exposure during the prenatal, neonatal, or adult periods have reported a range of neurodevelopmental and behavioral effects, [16,17] including hyperactivity $[18,19]$. In the present CCCEH cohort, prenatal exposure to $\mathrm{PAH}$ measured by prenatal air monitoring or $\mathrm{B}[\mathrm{a}] \mathrm{P}-$ DNA adducts in maternal or umbilical cord blood at delivery was associated with developmental delay at age 3 [20], reduced IQ at age 5 [21], and symptoms of anxiety/depression and attention problems at ages 6-7 [6].

Attention-deficit/hyperactivity disorder (ADHD) is the most common behavioral disorder diagnosed in children [22] and is often accompanied by anxiety and depression [23-26]. In our cohort, ADHD behavior problems and anxiety/depression at age 9 were significantly correlated $(\mathrm{r}=0.43, \mathrm{p}<0.0001)$. Children with ADHD are at increased risk of substance abuse, conduct, and mood disorders [27-30]. Family history, certain environmental contaminants, alcohol use, maternal smoking during pregnancy, pregnancy and delivery complications, and psychosocial adversity have been implicated or identified as risk factors for ADHD $[31,32]$.

Prior data on air pollution and ADHD are suggestive. For example, a cross-sectional study found an association between ambient particulate matter $\left(\mathrm{PM}_{10}\right)$ and childhood ADHD [33]. In a longitudinal study, estimated exposure during infancy to elemental black carbon, based on air sampling data and land use regression modeling, was significantly associated with ADHDrelated symptoms [34]. Another cohort study reported an association between attention and children's lifetime exposure to black carbon based on children's residence and a spatiotemporal model [35]. Ours is the first report of associations between individual measures of early-life exposure to PAH pollutants and ADHD behavior problems in children.

\section{Methods}

\section{Sample selection}

A complete description of the NYC cohort appears elsewhere [20,36]. Briefly, African-American and Dominican women who resided in Washington Heights, Harlem, or the South Bronx in NYC, U.S., were recruited between 1998 and 2006 through local prenatal care clinics. Enrollment was restricted to women who were non-active cigarette smokers; ages 18-35; non-users of other tobacco products or illicit drugs; free of diabetes, hypertension, or known HIV; and who had initiated prenatal care by the $20^{\text {th }}$ week of pregnancy. The Institutional Review Board of the Columbia University Medical Center approved the study. Mothers signed a consent form, approved by the IRB, for themselves and their children at the time of enrollment and at every subsequent visit. The children sign an IRB-approved assent form beginning at age 7. The consent and assent forms are available in English and Spanish and clearly explain the study goals and procedures.

The sample included in the present analysis is composed of the children who had available data on at least one adduct measure (maternal or newborn), the CPRS and the CBCL assessments, and all covariates of interest $(\mathrm{N}=250)$.

\section{Maternal/child characteristics and home caretaking environment}

Demographic, health and environmental conditions. A 45-minute structured questionnaire was administered by a trained bilingual interviewer during the last trimester of pregnancy to obtain demographic information, residential history, and health and environmental data such as active smoking (to confirm nonactive smoking status) and passive smoking [36]. The questionnaire also elicited information on dietary PAH (consumption of broiled, fried, grilled or smoked meat), and socioeconomic information related to income and education. Postnatal interviews were administered in person at 6 months and annually thereafter to determine changes in residence, exposure to environmental tobacco smoke (ETS), and health and environmental conditions.

Maternal demoralization. Maternal demoralization, a measure of maternal nonspecific psychological distress that has been linked to neurodevelopment [37-39], was measured at each visit by the Psychiatric Epidemiologic Research Instrument Demoralization Scale (PERI-D) [40].

Non-verbal intelligence. The Test of Non-Verbal Intelligence-Second Edition (C-TONI-2) [41] was administered to the mothers when the child was about 3 years old.

Home assessment. Caldwell and Bradley's Home Observation for Measurement of the Environment (HOME) [42] was administered in the home by research workers, also when the child was about 3 years old, to assess physical and interactive characteristics of the child rearing environment.

Maternal ADHD. At the child's 7 year visit, mothers completed the Conners Adult ADHD Rating Scales (CAARS) [43]. Given the high heritability rate of ADHD [44], maternal ADHD symptoms on the CAARS were included as a covariate in our analyses.

Ghild anxiety/depression. Childhood ADHD and anxiety/depression are frequently comorbid conditions [24]. The continuous score for symptoms of anxiety/depression on the CBCL at age 9 [45] was included as a covariate.

\section{Independent variables}

Prenatal exposure: PAH-DNA adducts. Following delivery, maternal blood and umbilical cord blood samples were collected. Within several hours following collection, samples were 
transported to the CCCEH Molecular Epidemiology Laboratory, processed, and stored at $-70^{\circ} \mathrm{C}$. $\mathrm{B}[\mathrm{a}] \mathrm{P}-\mathrm{DNA}$ adducts in extracted white blood cell DNA were analyzed using the high performance liquid chromatography (HPLG)/fluorescence method which detects $\mathrm{B}[\mathrm{a}] \mathrm{P}$ tetraols $[12,46]$. Not all participants had adequate DNA quantity for adduct analysis.

Postnatal exposure: urinary PAH metabolites. At the CDC, a suite of PAH metabolites was measured in spot urine (collected from the child at ages 3 and 5) using automated liquidliquid extraction and gas chromatography/isotope dilution highresolution mass spectrometry [47-49]. Although PAH urinary metabolite have a short lifetime (half-life of 6-35 hours) [50], in conditions of chronic exposure they provide a useful measure of exposure to $\mathrm{PAH}[47,48]$. Specific gravity (SG) measurements were used to control for urinary dilution of the samples using the following formula: freshweight metabolites for the subject*(mean SG-1)/(SG for that subject-1) $[51,52]$.

\section{Behavioral outcomes}

ADHD behavior problems were assessed using two complementary parent-report instruments: the CBCL for ages 6-18 (CBCL) [53] and the CPRS- Revised: Long Version [54]. The CBCL is a screening instrument assessing childhood competencies, adaptive functioning, and problems [45]. The CPRS is a focused assessment of childhood ADHD and its common comorbid disorders $[54,55]$. Both are widely used instruments that measure ADHD problems and attention function and have been used to study their associations with diverse environmental contaminants [56-59]. Both instruments yield scales derived from the DSM-IV [60] that are intended to screen for ADHD-behavior problems and indicate those children requiring follow-up. Mothers selfadministered the 80-item CPRS [54] and the 118-item CBCL [53] when their children were 9 years old, under the guidance of trained research workers. Outcomes analyzed included the CBCL DSM-oriented Attention Deficit/Hyperactivity Problems scale, and the CPRS ADHD Index and DSM-IV subscales (denoted as "Total", "Inattentive", and "Hyperactive-Impulsive"). The "Total" DSM-IV measure comprises the "Inattentive" and "Hyperactive-Impulsive" subscales. For both instruments, the child's responses were scored and summed to a raw score. T-scores were derived from raw scores based on the normative comparison sample as described in the administration manual and used to determine the child's classification [53,54]. On the CBCL DSMoriented Attention Deficit/Hyperactivity Problems score, children above the $93^{\text {rd }}$ percentile were classified as "borderline clinical", and those below the $93^{\text {rd }}$ percentile were classified in the normal range [53]. The CPRS DSM-IV subscales and ADHD Index scores were dichotomized based on the classification of a $\mathrm{T}$ score $>65$ as "moderately to markedly atypical" and a T score $\leq 65$ as "in the normal range" [54].

\section{Statistical Analysis}

As in prior analyses [6], adduct levels were dichotomized as detectable/non-detectable ("high/low"), with detectable levels observed in $42 \%$ of maternal and $46 \%$ of cord blood samples in the whole cohort. Dichotomization of exposure variables is less vulnerable to measurement error and permits comparison of the most highly exposed children to children with lower exposure. In our analyses, (1-hydroxynaphthalene, 2-hydroxynaphthalene, 2-hydroxyfluorene, 3-hydroxyfluorene, 9-hydroxyfluorene, 1hydroxyphenanthrene, 2-hydroxyphenanthrene, 3-hydroxyphenanthrene, 4-hydroxyphenanthrene) were summed to provide a composite measure denoted "PAH metabolites". PAH metabolites in child urine at ages 3 or 5 were dichotomized at the respective medians for the entire cohort and treated as "high/low". In terms of data analysis, the age 5 metabolite level was preferentially selected, but if that measure was missing, the age 3 metabolite level was used. In secondary analyses, adducts and PAH metabolites were also treated as a continuous variable after $\log$ transformation.

Covariates were selected based on whether they were significant contributors to the model (at $\mathrm{p} \leq 0.1$ ) for at least one of the outcomes and included: prenatal ETS exposure, child's sex, child's ethnicity, child's gestational age, mother's intelligence, mother's completed years of education prior to birth of the child, maternal prenatal demoralization, maternal ADHD symptoms, child's exact age at assessment (in months), the quality of the early home caretaking environment, and season at time of monitoring (heating vs. non-heating) (Table 1). We further adjusted for child anxiety/ depression at age 9 since it is a well-documented comorbid condition with ADHD and symptoms overlap [24]. Moreover, we have previously found associations of PAH with child anxiety/ depressive symptoms [6]. Dietary PAH, measured prenatally during the third trimester, was not a predictor of outcomes at $\mathrm{p} \leq 0.1$. The associations between the dichotomized PAH exposure variables and continuous raw scores and dichotomized $\mathrm{T}$ scores for ADHD-related behavior were analyzed by Poisson and logistic regression, respectively.

\section{Results}

Maternal and cord adducts were not significantly correlated with prenatally air monitored PAH, ETS, or dietary PAH.

Table 1 presents the socio-demographic, outcome, and exposure characteristics of the children who had available data on maternal or cord adducts, stratifying on whether or not they had data on neurobehavioral outcomes and covariates of interest and were thus included $(\mathrm{N}=250)$ or not included $(\mathrm{N}=364)$ in the analysis. The two groups were similar except that the group included had a higher proportion of females and were younger at the CPRS assessment, though all assessments were given at approximately age 9 . The level of adducts and percentage characterized as high vs. low did not differ between those included and not included. Comparing the group included $(\mathrm{N}=250)$ with those children who did not have maternal or cord adduct data $(\mathrm{N}=111)$, there were differences in terms of exact age at assessment for the CBCL and CPRS, home inventory scores, and percentage of mothers that had completed high school (data not shown).

Table 2 summarizes the distribution of CBCL and CPRS scores in the entire sample. Table 3 shows the number of children in the borderline or clinical range on the CBCL, and the number in the moderately to markedly atypical range on the CPRS. Consistent with other studies, there was substantial overlap between the number of children categorized in the moderately to markedly atypical range on the Hyperactive-Impulsive and Inattentive problems, as shown in Figure 1.

Table 4 summarizes the associations between maternal $(\mathrm{N}=233)$ and cord adduct $(\mathrm{N}=162)$ exposure and CBCL DSMoriented Attention Deficit/Hyperactivity problems and all CPRS outcomes, adjusting for postnatal $\mathrm{PAH}$ exposure and selected covariates. When considering outcomes analyzed as continuous raw scores, all CPRS subscales were positively and significantly associated with high maternal adduct exposure. After dichotomizing the outcome measures, those with high maternal adducts had odds of being categorized as moderately to markedly atypical on the DSM-IV Inattentive and DSM-IV Total scales 5.06 (95\% CI $[1.43,17.93])$ and 3.37 (95\% CI [1.10, 10.34]) times greater than those with low maternal adducts. High maternal adduct exposure 
Table 1. Characteristics of the children included in the analysis and those not included due to missing data.

\begin{tabular}{|c|c|c|c|}
\hline & $\begin{array}{l}\text { Subjects included in } \\
\text { the analysis }(\mathrm{N}=250)^{\mathrm{a}}\end{array}$ & $\begin{array}{l}\text { Subjects not included in } \\
\text { the analysis }(N=364)^{b}\end{array}$ & \\
\hline Variables & Mean $\pm S D$ or $\%$ & Mean \pm SD or $\%$ & $\mathrm{p}$-value \\
\hline High maternal adducts $^{c}$ & $37.34 \%$ & $44.25 \%$ & 0.10 \\
\hline High cord adducts ${ }^{c}$ & $39.51 \%$ & 49. $37 \%$ & 0.07 \\
\hline High urinary PAH metabolites at ages 3 or $5^{\mathrm{d}}$ & $49.20 \%$ & $55.07 \%$ & 0.22 \\
\hline Log-transformed urinary PAH metabolites at ages 3 or $5^{\mathrm{e}}$ & $9.02 \pm 0.89$ & $9.03 \pm 0.80$ & 0.86 \\
\hline Log-transformed maternal adduct (per $10^{8}$ nucleotides) & $-1.73 \pm 0.47$ & $-1.68 \pm 0.48$ & 0.20 \\
\hline Log-transformed cord adduct (per $10^{8}$ nucleotides) & $-1.67 \pm 0.53$ & $-1.59 \pm 0.53$ & 0.13 \\
\hline $\begin{array}{l}\text { CBCL DSM-oriented Attention Deficit/Hyperactivity Problems (\% with } \\
\text { borderline or clinical diagnosis })^{f}\end{array}$ & $7.20 \%$ & $10.66 \%$ & 0.32 \\
\hline \multicolumn{4}{|l|}{ CPRS subscales (\% categorized as moderately to markedly atypical) ${ }^{9}$} \\
\hline ADHD Index & $8.40 \%$ & $7.87 \%$ & 1.00 \\
\hline DSM-IV Inattentive & $8.40 \%$ & $5.51 \%$ & 0.41 \\
\hline DSM- IV Hyperactive- Impulsive & $10.80 \%$ & $14.17 \%$ & 0.40 \\
\hline DSM-IV Total & $10.40 \%$ & $7.87 \%$ & 0.47 \\
\hline Prenatal ETS exposure (\% yes) & $33.20 \%$ & $37.36 \%$ & 0.30 \\
\hline Child sex (\% female) & $57.60 \%$ & $48.35 \%$ & $0.03^{*}$ \\
\hline Child ethnicity (AA\%) ${ }^{\text {h }}$ & $40.00 \%$ & $33.24 \%$ & 0.09 \\
\hline Gestational age (in weeks) ${ }^{i}$ & $39.35 \pm 1.37$ & $39.34 \pm 1.44$ & 0.94 \\
\hline Maternal intelligence ${ }^{j}$ & $20.82 \pm 8.78$ & $20.25 \pm 8.62$ & 0.47 \\
\hline Maternal education ( $\% \geq$ high school education) & $64.80 \%$ & $59.83 \%$ & 0.24 \\
\hline Maternal demoralization score & $1.15 \pm 0.61$ & $1.18 \pm 0.67$ & 0.67 \\
\hline Maternal ADHD (CAARS ADHD index raw score) ${ }^{k}$ & $38.79 \pm 8.87$ & $37.67 \pm 7.16$ & 0.15 \\
\hline $\mathrm{CBCL}_{\text {age }}$ (in months) ${ }^{\prime}$ & $108.01 \pm 1.83$ & $108.78 \pm 4.60$ & 0.14 \\
\hline CPRS age (in months)' & $107.96 \pm 2.02$ & $109.15 \pm 4.97$ & $0.03^{*}$ \\
\hline Home environment $^{\mathrm{m}}$ & $40.09 \pm 5.94$ & $39.33 \pm 6.09$ & 0.18 \\
\hline Heating season $(\% \text { yes })^{n}$ & $54.0 \%$ & $56.52 \%$ & 0.64 \\
\hline Child anxiety/depression (CBCL anxiety/depression raw score) ${ }^{\circ}$ & $2.74 \pm 3.02$ & $2.53 \pm 2.80$ & 0.53 \\
\hline
\end{tabular}

${ }^{a}$ Subjects were included if they had data for maternal adducts and/or cord adducts, as well as data on CBCL, CPRS outcome and all covariates of interest.

${ }^{b}$ Subjects not included are those that had available data on cord and/or maternal adducts but were missing data on the CBCL, CPRS outcomes and/or any covariates included in the final model.

"Adduct levels were dichotomized as detectable/non-detectable ("high/low").

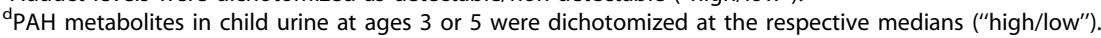

${ }^{e}$ Children with urinary PAH metabolite measurement at ages 3 or 5 .

${ }^{f}$ Based on T score. Borderline or clinical defined as percentile $\geq 93^{\text {rd }}$.

${ }^{9}$ Based on T score. Moderately to markedly atypical defined as T-score $>65$.

${ }^{\mathrm{h}}$ Percent African American; the remainder are Dominican.

'Based on medical record data.

jonverbal intelligence measured by the TONI-2.

${ }^{\mathrm{k}}$ Measure of maternal ADHD.

'Age at administration.

${ }^{m}$ HOME Inventory as a measure of the home caretaking environment.

${ }^{\mathrm{n}}$ Third trimester in heating season.

${ }^{\circ}$ Based on CBCL Anxious/Depressed Syndrome Scale measured at age 9.

*p-value $<0.05$.

doi:10.1371/journal.pone.0111670.t001

was also significantly and positively associated with the CDCL DSM-oriented Attention Deficit/Hyperactivity Problems scale, though results did not reach statistical significance.

In separate models with log transformed adduct and metabolite values as the exposure variables, the direction and significance of the associations between adducts and outcomes were the same as the models with the dichotomized exposure with the exception of the CBCL DSM-oriented attention deficit hyperactivity scale raw score and CPRS DSM-IV Total scale raw score, which became borderline significant $(\mathrm{p}=0.06$, and $\mathrm{p}=0.08$, respectively) (data not shown).

Parallel analyses in the smaller number of subjects with available cord adduct data $(\mathrm{N}=162)$ exposure found nonsignificant or borderline significant associations with all outcomes (Table 4).

\section{Discussion}

The present results suggest that high prenatal exposure, taking into account the potential effects of postnatal PAH exposure, may 
Table 2. Distribution of CBCL and CPRS Scores in children at age $9\left(\mathrm{~N}=250^{\mathrm{a}}\right)$.

\begin{tabular}{|c|c|c|c|c|c|}
\hline \multirow[b]{2}{*}{ Outcomes } & \multicolumn{2}{|c|}{ Score Range } & \multicolumn{2}{|c|}{ Mean of Scores } & \multirow[t]{2}{*}{$\begin{array}{l}\text { Percent in Borderline or clinical or } \\
\text { Moderately to markedly atypical range }\end{array}$} \\
\hline & T Score & Raw Score & T score & Raw score & \\
\hline $\begin{array}{l}\text { CBCL DSM-oriented Attention Deficit/ } \\
\text { Hyperactivity Problems }\end{array}$ & $50-80$ & $0-14$ & 53.9 & 3.1 & 7.2 \\
\hline \multicolumn{6}{|l|}{ CPRS subscales } \\
\hline ADHD Index & $40-89$ & $0-34$ & 49.8 & 6.4 & 8.4 \\
\hline DSM-IV Total & $40-90$ & $0-48$ & 50.8 & 9.2 & 10.4 \\
\hline DSM-IV Hyperactive- Impulsive & $41-90$ & $0-25$ & 52.8 & 4.7 & 10.8 \\
\hline DSM-IV Inattentive & $40-88$ & $0-25$ & 48.9 & 4.5 & 8.4 \\
\hline
\end{tabular}

${ }^{a}$ Children included in analysis with all covariates.

${ }^{b} \mathrm{CBCL}$ "borderline or clinical" defined as percentile $\geq 93^{\text {rd }}$; CPRS "moderately to markedly atypical" defined as T-score $>65$.

doi:10.1371/journal.pone.0111670.t002

increase the risk of ADHD behavior problems. ADHD is a disorder that is known to impact school performance, social relationships, and occupational performance [61-66]. In the U.S. the annual societal cost of illness for ADHD is estimated to be between $\$ 36$ and $\$ 52$ billion, and the annual cost per individual is estimated to be $\$ 12,005$ to $\$ 17,458(2005)[67,68]$.

To our knowledge, there have been no prior epidemiological studies on the role of pre- and post-natal PAH exposure, here measured by chemical-specific biomarkers, on ADHD in schoolage children. Prior experimental research and limited epidemiological studies have suggested links between PM and air pollution (elemental carbon and black carbon) and ADHD symptoms [3335]. In the present longitudinal study high maternal adduct levels were not significantly associated with Attention Deficit/Hyperactivity problems on the CBCL screening test, but on the more detailed CPRS, consistently significant associations with a number of ADHD-related outcomes were seen. In particular, significant associations between high maternal adducts and the DSM-IV Total and DSM-IV Inattentive scales were observed in models treating CPRS scores as continuous and dichotomous outcomes. Consistency in the results across both of these outcome measures strengthens the conclusion that inattention is associated with prenatal PAH exposure.

The maternal and cord adducts were significantly but only modestly correlated $(r=0.28, p<0.0001)$, probably because of the immaturity of the metabolic/detoxification and DNA repair systems in the fetus compared to the adult [69] and the differing genetic profiles of the mother and the child. The stronger relationship between the maternal adducts and ADHD-related outcomes than between the cord adducts and the same outcomes could be attributable to the effects of exposure on placental function and/or the fact that high levels of maternal adducts indicate that the mother has been highly exposed and is an efficient activator of $\mathrm{PAH}$, resulting in higher transplacental exposure to reactive PAH intermediates. We used urinary PAH metabolites to assess postnatal exposure. This biomarker has been employed in many studies as an indicator of $\mathrm{PAH}$ exposure in the general population [70]. Although they represent recent exposure [71], the metabolites can provide a chronic measure of ambient $\mathrm{PAH}$ in populations with constant exposure [72].

The mechanisms by which PAH exposure might affect the developing brain are not fully understood. Several pathways have been suggested including endocrine disruption [73-75], binding to receptors for placental growth factors resulting in decreased exchange of oxygen and nutrients [76], binding to the human Ah receptor to induce P450 enzymes [77], DNA damage resulting in activation of apoptotic pathways [78-80], oxidative stress due to inhibition of the brain antioxidant scavenging system [81], and epigenetic alterations [82]. The prenatal period is critical because of the extensive structural and cellular-level changes that occur during this stage of development. However, because brain development and growth occurs throughout childhood, postnatal exposures to environmental pollutants may also affect children's neurodevelopment and behavior [83].

The strengths of the study include our ability to account for a number of potential confounding variables and to draw upon

Table 3. Number of children scoring in the borderline or clinical range on the $C B C L$ and in the moderately to markedly atypical range on the CPRS in the analyses with maternal adducts or cord adducts ${ }^{a}$.

\begin{tabular}{lll}
\hline & & \\
\hline & Maternal Adducts (N= 233) & Cord Adducts (N= 162) \\
\hline${\text { CBCL DSM-oriented Attention Deficit/Hyperactivity Problems (Borderline or clinical }{ }^{\text {b }} \text { ) }}$ & 18 & 15 \\
CPRS subscales (Moderately to markedly atypical $^{\text {}}$ ) & & 14 \\
ADHD Index & 20 & 19 \\
DSM-IV Total & 25 & 19 \\
DSM-IV Hyperactive Impulsive & 26 & 15 \\
DSM-IV Inattentive & 20 & \\
\hline
\end{tabular}

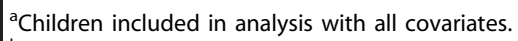

${ }^{b} \mathrm{CBCL}$ - Borderline or clinical defined as percentile $\geq 93^{\text {rd }}$; CPRS- Moderately to markedly atypical defined as T-score $>65$.

doi:10.1371/journal.pone.0111670.t003 
Maternal adduct subsample $(\mathrm{N}=233)^{\mathrm{b}}$

Hyperactive-Impulsive Inattentive

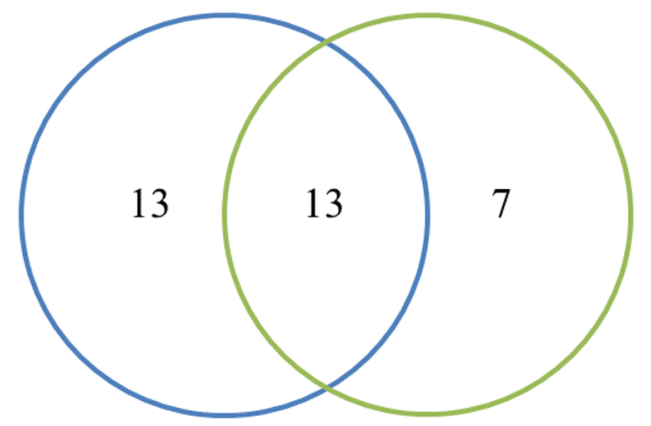

Cord adduct subsample $(\mathrm{N}=162)^{\mathrm{b}}$

Hyperactive-Impulsive Inattentive

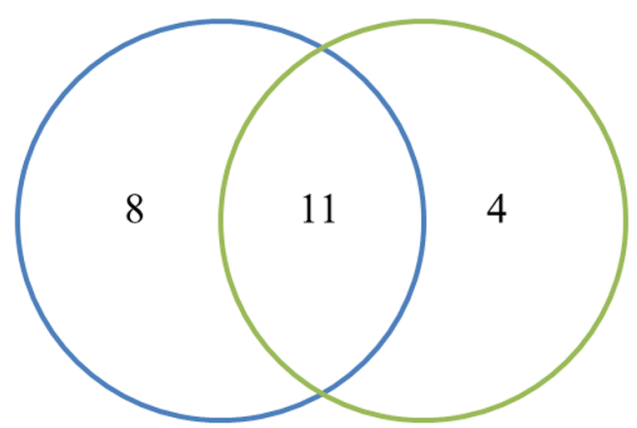

${ }^{a}$ CBCL- Borderline or clinical defined as percentile > 93rd; CPRS- Moderately to markedly atypical defined as T-score $>65$

${ }^{b}$ Children included in analysis with all covariates

Figure 1. Number of children categorized as moderately to markedly atypical on the CPRS DSM-IV Hyperactive Impulsive and CPRS DSM-IV Inattentive Subscales ${ }^{a}$.

doi:10.1371/journal.pone.0111670.g001

individual pre- and post-natal exposure data from biomarker and questionnaire data. We were able to use two complementary ageappropriate instruments to measure ADHD-related behaviors. The CBCL screens for various childhood behavior problems, including ADHD [53]. The CPRS tests specifically for ADHD and related problem behaviors and is intended to be more diagnostic than the CBCL [54]. Due to the prospective nature of our cohort study we were able to assess the association between environmental exposures sustained prenatally and future development of ADHD-related behaviors in childhood.

A limitation of the study is that unmeasured factors such as other pollutants, stress, and noise may have contributed to residual confounding. In addition, the number of children with moderately to markedly atypical outcomes on the CPRS (cases) was small, resulting in fairly wide confidence intervals around the odds ratios. However, the confidence intervals around the effect estimates for the continuous outcomes are much tighter. Although of interest, we

Table 4. Associations between PAH Exposure and CBCL DSM-oriented Attention Deficit/Hyperactivity problems and ADHD Behavior Problems on the CPRS Subscales adjusting for postnatal exposure ${ }^{a}$.

\begin{tabular}{|c|c|c|}
\hline & Maternal Adduct $(\mathrm{N}=\mathbf{2 3 3})$ & Cord Adduct $(\mathrm{N}=162)$ \\
\hline \multicolumn{3}{|l|}{ Outcomes analyzed continuously } \\
\hline & $\beta_{\text {adducts }}\left(95 \% \mathrm{Cl}^{\mathrm{b}}\right)$ & $\beta_{\text {adducts }}\left(95 \% \mathrm{Cl}^{\mathrm{b}}\right)$ \\
\hline CBCL DSM-oriented Attention Deficit/Hyperactivity Problems & $0.13(-0.03,0.29)$ & $-0.04(-0.23,0.15)$ \\
\hline \multicolumn{3}{|l|}{ CPRS subscales } \\
\hline ADHD Index & $0.14(0.03,0.25)^{*}$ & $-0.06(-0.19,0.07)$ \\
\hline DSM-IV Total & $0.16(0.07,0.26)^{*}$ & $0.009(-0.10,0.12)$ \\
\hline DSM-IV Hyperactive-Impulsive & $0.16(0.03,0.29)^{*}$ & $0.10(-0.05,0.26)$ \\
\hline DSM-IV Inattentive & $0.17(0.04,0.31)^{*}$ & $-0.09(-0.25,0.06)$ \\
\hline \multicolumn{3}{|l|}{ Outcomes analyzed dichotomouslyc } \\
\hline & $\mathrm{OR}^{\mathrm{b}}\left(95 \% \mathrm{Cl}^{\mathrm{b}}\right)$ & $\mathrm{OR}^{\mathrm{b}}\left(95 \% \mathrm{Cl}^{\mathrm{b}}\right)$ \\
\hline CBCL DSM-oriented Attention Deficit/Hyperactivity Problems & $1.48(0.38,5.79)$ & $1.17(0.24,5.66)$ \\
\hline \multicolumn{3}{|l|}{ CPRS subscales } \\
\hline ADHD Index & $1.83(0.61,5.54)$ & $0.93(0.22,4.01)$ \\
\hline DSM-IV Total & $3.37(1.10,10.34) *$ & $1.70(0.47,6.17)$ \\
\hline DSM-IV Hyperactive-Impulsive & $1.58(0.55,4.52)$ & $1.04(0.30,3.61)$ \\
\hline DSM-IV Inattentive & $5.06(1.43,17.93)^{*}$ & $1.32(0.31,5.56)$ \\
\hline \multicolumn{3}{|c|}{$\begin{array}{l}{ }^{a} \text { Adjusting for postnatal PAH exposure (measured by metabolites at ages } 3 \text { or } 5 \text {, adjusted for specific gravity), prenatal ETS, chil } \\
\text { gestational age, maternal demoralization, heating season, HOME caretaking environment, maternal intelligence, child age at a } \\
\text { depression at age } 9 \text {. } \\
{ }^{b} \text { OR stands for odds Ratio; } \mathrm{Cl} \text { stands for Confidence Interval. } \\
{ }^{c} \mathrm{CBCL} \text { - Borderline or clinical defined as percentile } \geq 93^{\text {rd }} \text {; CPRS- Moderately to markedly atypical defined as T-score }>65 \text {. } \\
{ }^{*} \text { p-value }<0.05 \text {. } \\
\text { doi: } 10.1371 \text { /journal.pone. } 0111670 . t 004\end{array}$} \\
\hline
\end{tabular}


did not have complete data on exposure to lead or mercury and were unable to account for this in our models. We were also unable to evaluate the effects of individual postnatal PAH metabolites that may have differing toxicities; however benzo[a]pyrene is an important, toxic member of the class of PAH. Finally, generalizability was reduced by the ethnicity restriction of our cohort (African-American and Dominican) and our exclusion of active smokers, illicit drug users, and women with pre-existing disease.

\section{Conclusions}

In conclusion, this study provides evidence that early exposure to environmental $\mathrm{PAH}$ may contribute to $\mathrm{ADHD}$ behavior problems in children. The results require confirmation but are of concern since children with ADHD are at greater risk of risktaking behaviors [84], poor academic performance [85], and lower earnings in adulthood [86,87]. ADHD imposes large costs on society, estimated to range between $\$ 36$ billion and $\$ 52$ billion annually $[67,68]$.

PAH are widespread in urban environments worldwide largely as a result of fossil fuel combustion. Fortunately, it is possible to reduce airborne $\mathrm{PAH}$ concentrations using currently available pollution controls, greater energy efficiency, the use of alternative energy sources, and regulatory intervention to control polluting sources.

\section{Acknowledgments}

Funding was provided by the National Institute for Environmental Health Sciences (NIEHS) and the U.S. Environmental Protection Agency (US

\section{References}

1. Bostrom CE, Gerde P, Hanberg A, Jernstrom B, Johansson C, et al. (2002) Cancer risk assessment, indicators, and guidelines for polycyclic aromatic hydrocarbons in the ambient air. Environ Health Perspect 110: 451-488.

2. Perera FP, Illman SM, Kinney PL, Whyatt RM, Kelvin EA, et al. (2002) The challenge of preventing environmentally related disease in young children: community-based research in New York City. Environ Health Perspect 110: 197-204.

3. Woodruff TJ, Parker JD, Kyle AD, Schoendorf KC (2003) Disparities in exposure to air pollution during pregnancy. Environmental Health Perspectives 111: $942-946$.

4. Jerrett M (2009) Global Geographies of Injustice in Traffic-Related Air Pollution Exposure. Epidemiology 20: 231-233 210.1097/EDE.1090b1013e318197 $76 \mathrm{a} 31819771$.

5. Morello-Frosch R, Zuk M, Jerrett M, Shamasunder B, Kyle AD (2011) Understanding The Cumulative Impacts Of Inequalities In Environmental Health: Implications For Policy. Health Affairs 30: 879-887.

6. Perera FP, Tang D, Wang S, Vishnevetsky J, Zhang B, et al. (2012) Prenatal Polycyclic Aromatic Hydrocarbon (PAH) Exposure and Child Behavior at age 6-7. Environ Health Perspect.

7. Mooney LA, Santella RM, Covey L, Jeffrey AM, Bigbee W, et al. (1995) Decline of DNA damage and other biomarkers in peripheral blood following smoking cessation. Cancer Epidemiol Biomarkers Prev 4: 627-634.

8. Godschalk RWL, Van Schooten FJ, Bartsch H (2003) A critical evaluation of DNA adducts as biological markers for human exposure to polycyclic aromatic compounds. Journal of Biochemistry and Molecular Biology 36: 1-11.

9. Veglia F, Loft S, Matullo G, Peluso M, Munnia A, et al. (2008) DNA adducts and cancer risk in prospective studies: a pooled analysis and a meta-analysis. Carcinogenesis 29: 932-936.

10. Anderson LM, Diwan BA, Fear NT, Roman E (2000) Critical windows of exposure for children's health: cancer in human epidemiological studies and neoplasms in experimental animal models. Environ Health Perspect 108: 573594.

11. National Research Council (1993) Toxicity Testing and Strategies to Determine Needs and Priorities. Washington, D.C.: National Academy Press.

12. Perera FP, Tang D, Jedrychowski W, Hemminki K, Santella RM, et al. (2004) Biomarkers in maternal and newborn blood indicate heightened fetal susceptibility to procarcinogenic DNA damage. Environ Health Perspect 112: 1133-1136.

13. Grandjean P, Landrigan PJ (2006) Developmental neurotoxicity of industrial chemicals. Lancet 368: 2167-2178.

14. Stein J, Schettler T, Wallinga D, Valenti M (2002) In harm's way: toxic threats to child development. J Dev Behav Pediatr 23: S13-22.

15. Shonkoff JP, Garner AS, Committee on Psychosocial Aspects of Child And Family Health, Committee on Early Childhood, Adoption, and Dependent
EPA): NIEHS/EPA P01ES09600/R82702701, NIEHS/EPA P01ES09600/RD832141, NIEHS/EPA P01ES09600/RD834509, NIEHS R01ES08977. This publication was also made possible in part by US EPA grants RD832096, the John \& Wendy Neu Family Foundation, the New York Community Trust, Trustees of the Blanchette Hooker Rockefeller Fund, and an anonymous foundation. Funding from all the institutions listed was used towards the design and conduct of the study; collection, management, analysis, and interpretation of the data; and the preparation, review, and approval of the manuscript. Its contents are solely the responsibility of the grantee and do not necessarily represent the official views of the US EPA. Further, US EPA does not endorse the purchase of any commercial products or services mentioned in the publication. Findings expressed in this paper are the opinions of the authors and do not necessarily reflect the official opinion of the Centers for Disease Control and Prevention.

Analysis of PAH metabolites was conducted at the Centers for Disease Control and Prevention, National Center for Environmental Health, Division of Laboratory Sciences, 4770 Buford Highway, Atlanta, Georgia 30341, United States, in the laboratory of Andreas Sjodin, PhD. We also thank Joanne Chin, MFA, at the Columbia Center for Children's Environmental Health, 722 W. $168^{\text {th }}$ Street, New York, NY 10032, United States, for assistance in manuscript preparation.

\section{Author Contributions}

Acquired the data: FPP HC AM TH SW VR. Interpreted the data: FPP HC AM TH SW VR. Drafted the article or revised it critically for important intellectual content: FPP ELR AM SW VR. Final approval of the version to be published: FPP HC DT ELR JH RLM AM TH SW VR.

Care, Section on Developmental and Behavioral Pediatrics (2012) The Lifelong Effects of Early Childhood Adversity and Toxic Stress. Pediatrics 129: E232E246.

16. Brown LA, Khousbouei H, Goodwin JS, Irvin-Wilson CV, Ramesh A, et al. (2007) Down-regulation of early ionotrophic glutamate receptor subunit developmental expression as a mechanism for observed plasticity deficits following gestational exposure to benzo(a)pyrene. Neurotoxicology 28: 965-978.

17. Wormley DD, Ramesh A, Hood DB (2004) Environmental contaminantmixture effects on CNS development, plasticity, and behavior. Toxicol Appl Pharmacol 197: 49-65.

18. Grova N, Valley A, Turner JD, Morel A, Muller CP, et al. (2007) Modulation of behavior and NMDA-R1 gene mRNA expression in adult female mice after subacute administration of benzo(a)pyrene. Neurotoxicology 28: 630-636.

19. Schellenberger MT, Grova N, Farinelle S, Willième S, Schroeder H, et al. (2013) Modulation of benzo[a]pyrene induced neurotoxicity in female mice actively immunized with a $\mathrm{B}[\mathrm{a}] \mathrm{P}$-diphtheria toxoid conjugate. Toxicology and Applied Pharmacology 271: 175-183.

20. Perera FP, Rauh V, Whyatt RM, Tsai WY, Tang D, et al. (2006) Effect of prenatal exposure to airborne polycyclic aromatic hydrocarbons on neurodevelopment in the first 3 years of life among inner-city children. Environ Health Perspect 114: 1287-1292.

21. Perera FP, Li Z, Whyatt R, Hoepner L, Wang S, et al. (2009) Prenatal polycyclic aromatic hydrocarbon exposure and child intelligence at age 5. Pediatrics 124 : e195-e202.

22. Bostic JQ, Prince JB (2008) Child and adolescent psychiatric disorders. In: Stern TA, Rosenbaum JF, Fava M, Biederman J, Rauch SL, editors.Massachusetts General Hospital Comprehensive Clinical Psychiatry. 1st ed. Philadelphia, PA: Elsevier Mosby.

23. Wilens TE, Biederman J, Brown S, Tanguay S, Monuteaux MC, et al. (2002) Psychiatric Comorbidity and Functioning in Clinically Referred Preschool Children and School-Age Youths With ADHD. Journal of the American Academy of Child \& Adolescent Psychiatry 41: 262-268.

24. Spencer TJ, Biederman J, Mick E (2007) Attention-deficit/hyperactivity disorder: diagnosis, lifespan, comorbidities, and neurobiology. J Pediatr Psychol 32: $631-642$.

25. Biederman J, Faraone SV, Keenan K, Benjamin J, Krifcher B, et al. (1992) Further Evidence for Family-Genetic Risk-Factors in Attention-Deficit Hyperactivity Disorder - Patterns of Comorbidity in Probands and Relatives in Psychiatrically and Pediatrically Referred Samples. Archives of General Psychiatry 49: 728-738.

26. Spencer T, Biederman J, Wilens T (1999) Attention-deficit/hyperactivity disorder and comorbidity.Pediatr Clin North Am 46: 915-927, vii.

27. Gharach A, Yeung E, Glimans T, Lillie E (2011) Childhood Attention-Deficit/ Hyperactivity Disorder and Future Substance Use Disorders: Comparative 
Meta-Analyses. Journal of the American Academy of Child and Adolescent Psychiatry 50: 9-21.

28. Lee SS, Humphreys KL, Flory K, Liu R, Glass K (2011) Prospective association of childhood attention-deficit/hyperactivity disorder (ADHD) and substance use and abuse/dependence: a meta-analytic review. Clin Psychol Rev 31: 328-341.

29. Groenman AP, Oosterlaan J, Rommelse N, Franke B, Roeyers H, et al. (2013) Substance use disorders in adolescents with attention deficit hyperactivity disorder: a 4-year follow-up study. Addiction 108: 1503-1511.

30. Shaw M, Hodgkins P, Caci H, Young S, Kahle J, et al. (2012) A systematic review and analysis of long-term outcomes in attention deficit hyperactivity disorder: effects of treatment and non-treatment. BMC Med 10: 99.

31. Banerjee TD, Middleton F, Faraone SV (2007) Environmental risk factors for attention-deficit hyperactivity disorder. Acta Paediatr 96: 1269-1274

32. Froehlich TE, Anixt JS, Loe IM, Chirdkiatgumchai V, Kuan L, et al. (2011) Update on environmental risk factors for attention-deficit/hyperactivity disorder. Curr Psychiatry Rep 13: 333-344.

33. Siddique S, Banerjee M, Ray MR, Lahiri T (2011) Attention-deficit hyperactivity disorder in children chronically exposed to high level of vehicular pollution. Eur J Pediatr 170: 923-929.

34. Newman NC, Ryan P, Lemasters G, Levin L, Bernstein D, et al. (2013) Trafficrelated air pollution exposure in the first year of life and behavioral scores at 7 years of age. Environ Health Perspect 121: 731-736.

35. Chiu YHM, Bellinger DC, Coull BA, Anderson S, Barber R, et al. (2013) Associations between Traffic-Related Black Carbon Exposure and Attention in a Prospective Birth Cohort of Urban Children. Environ Health Perspect 121: 859-864.

36. Perera FP, Rauh V, Tsai WY, Kinney P, Camann D, et al. (2003) Effects of transplacental exposure to environmental pollutants on birth outcomes in a multi-ethnic population. Environ Health Perspect 111: 201-205.

37. Schuurmans C, Kurrasch DM (2013) Neurodevelopmental consequences of maternal distress: what do we really know? Clinical Genetics 83: 108-117.

38. Bergman K, Sarkar P, O’Connor TG, Modi N, Glover V (2007) Maternal Stress During Pregnancy Predicts Cognitive Ability and Fearfulness in Infancy. Journal of the American Academy of Child \& Adolescent Psychiatry 46: 1454-1463.

39. Barry TD, Dunlap ST, Cotten SJ, Lochman JE, Wells KC (2005) The Influence of Maternal Stress and Distress on Disruptive Behavior Problems in Boys. Journal of the American Academy of Child \& Adolescent Psychiatry 44: 265273.

40. Dohrenwend BS, Krasnoff L, Askenacy A, Dohrenwend B (1978) Exemplification of a method for scaling life events: the PERI life events scale. J Health Soc Behavior 19: 205-229.

41. Brown L, Sherbenou RJ, Johnson SK (1990) Test of non-verbal intelligence: a language-free measure of cognitive ability. 2nd edition. Austin, Tx: PRO-ED, Inc

42. Caldwell BM, Bradley RH (1979) Home observation for measurement of the environment. Little Rock, AK: University of Arkansas Press.

43. Conners C, Erhardt D, Sparrow E (1999) Conners' Adult ADHD rating scales: Technical manual. New York: Multi-Health Systems.

44. Todd RD, Rasmussen ER, Neuman RJ, Reich W, Hudziak JJ, et al. (2001) Familiality and heritability of subtypes of attention deficit hyperactivity disorder in a population sample of adolescent female twins. Am J Psychiatry 158: 18911898.

45. Achenbach T, Rescorla L (2001) Child Behavior Checklist for age 6-18. Burlington VT: ASEBA, 6-1-01 Edition.

46. Alexandrov K, Rojas M, Geneste O, Castegnaro M, Camus AM, et al. (1992) An improved fluorometric assay for dosimetry of benzo(a)pyrene diol-epoxideDNA adducts in smokers' lung: comparisons with total bulky adducts and aryl hydrocarbon hydroxylase activity. Cancer Res 52: 6248-6253.

47. Li Z, Romanoff LC, Trinidad DA, Hussain N, Jones RS, et al. (2006) Measurement of urinary monohydroxy polycyclic aromatic hydrocarbons using automated liquid-liquid extraction and gas chromatography/isotope dilution high-resolution mass spectrometry. Anal Chem 78: 5744-5751.

48. Li Z, Sandau CD, Romanoff LC, Caudill SP, Sjodin A, et al. (2008) Concentration and profile of 22 urinary polycyclic aromatic hydrocarbon metabolites in the US population. Environ Res 107: 320-331.

49. Miller RL, Garfinkel R, Lendor C, Hoepner L, Li Z, et al. (2010) Polycyclic aromatic hydrocarbon metabolite levels and pediatric allergy and asthma in an inner-city cohort. Pediatr Allergy Immunol 21: 260-267.

50. Jongeneelen FJ, van Leeuwen FE, Oosterink S, Anzion RB, van der Loop F, et al. (1990) Ambient and biological monitoring of cokeoven workers: determinants of the internal dose of polycyclic aromatic hydrocarbons. $\mathrm{Br} \mathrm{J}$ Ind Med 47: 454-461.

51. Hauser R, Meeker JD, Park S, Silva MJ, Calafat AM (2004) Temporal variability of urinary phthalate metabolite levels in men of reproductive age. Environ Health Perspect 112: 1734-1740.

52. Perera F, Vishnevetsky J, Herbstman JB, Calafat AM, Xiong W, et al. (2012) Prenatal bisphenol a exposure and child behavior in an inner-city cohort. Environ Health Perspect 120: 1190-1194.

53. Achenbach T, Rescorla L (2001) Manual for the ASEBA School-Age Forms \& Profiles. Burlington, VT: University of Vermont, Research Center for Children, Youth \& Families.

54. Conners CK (1997) Conners' Rating Scales- Revised (CRS-R): User's Manual Toronto, ON: Multi-Health Systems Inc.
55. Conners CK, Parker JDA, Sitarenios G, Epstein JN (1998) The Revised Conners' Parent rating Scale (CPRS-R): Factor structure, reliability, and criterion validity. Journal of Abnormal Child Psychology 26: 2567-2268.

56. Rodriguez-Barranco M, Lacasana M, Aguilar-Garduno C, Alguacil J, Gil F, et al. (2013) Association of arsenic, cadmium and manganese exposure with neurodevelopment and behavioural disorders in children: a systematic review and meta-analysis. Sci Total Environ 454-455: 562-577.

57. Cornelius MD, De Genna NM, Leech SL, Willford JA, Goldschmidt L, et al. (2011) Effects of prenatal cigarette smoke exposure on neurobehavioral outcomes in 10-year-old children of adolescent mothers. Neurotoxicol Teratol 33: $137-144$.

58. Bouchard M, Laforest F, Vandelac L, Bellinger D, Mergler D (2007) Hair manganese and hyperactive behaviors: pilot study of school-age children exposed through tap water. Environ Health Perspect 115: 122-127.

59. Wasserman GA, Staghezza-Jaramillo B, Shrout P, Popovac D, Graziano J (1998) The effect of lead exposure on behavior problems in preschool children. Am J Public Health 88: 481-486.

60. American Psychiatric Association, American Psychiatric Association, Task Force on DSM-IV (2000) Diagnostic and statistical manual of mental disorders: DSMIV-TR. Washington, DC: American Psychiatric Association. xxxvii, 943 p. p.

61. de Graaf R, Kessler RC, Fayyad J, ten Have M, Alonso J, et al. (2008) The prevalence and effects of adult attention-deficit/hyperactivity disorder (ADHD) on the performance of workers: results from the WHO World Mental Health Survey Initiative. Occup Environ Med 65: 835-842.

62. Kupper T, Haavik J, Drexler H, Ramos-Quiroga JA, Wermelskirchen D, et al. (2012) The negative impact of attention-deficit/hyperactivity disorder on occupational health in adults and adolescents. Int Arch Occup Environ Health 85: 837-847.

63. Wu SY, Gau SS (2013) Correlates for academic performance and school functioning among youths with and without persistent attention-deficit/ hyperactivity disorder. Res Dev Disabil 34: 505-515.

64. Jacobson LA, Ryan M, Denckla MB, Mostofsky SH, Mahone EM (2013) Performance Lapses in Children with Attention-Deficit/Hyperactivity Disorder Contribute to Poor Reading Fluency. Arch Glin Neuropsychol.

65. Ek U, Westerlund J, Holmberg K, Fernell E (2011) Academic performance of adolescents with ADHD and other behavioural and learning problems -a population-based longitudinal study. Acta Paediatr 100: 402-406.

66. Strine TW, Lesesne CA, Okoro CA, McGuire LC, Chapman DP, et al. (2006) Emotional and behavioral difficulties and impairments in everyday functioning among children with a history of attention-deficit/hyperactivity disorder. Prev Chronic Dis 3: A52.

67. CDC (2013) ADHD, Data and Statistics, National Center on Birth Defects and Developmental Disabilities.

68. Pelham WE, Foster EM, Robb JA (2007) The economic impact of attentiondeficit/hyperactivity disorder in children and adolescents. J Pediatr Psychol 32: 711-727.

69. Perera FP, Tang D, Whyatt R, Lederman SA, Jedrychowski W (2005) DNA damage from polycyclic aromatic hydrocarbons measured by benzo[a]pyreneDNA adducts in mothers and newborns from Northern Manhattan, the World Trade Center Area, Poland, and China. Cancer Epidemiol Biomarkers Prev 14: 709-714.

70. Castano-Vinyals G, D'Errico A, Malats N, Kogevinas M (2004) Biomarkers of exposure to polycyclic aromatic hydrocarbons from environmental air pollution. Occup Environ Med 61: e12.

71. Strickland P, Kang D, Sithisarankul P (1996) Polycyclic aromatic hydrocarbon metabolites in urine as biomarkers of exposure and effect. Environ Health Perspect 104 Suppl 5: 927-932.

72. Zhao ZH, Quan WY, Tian DH (1990) Urinary 1-Hydroxypyrene as an Indicator of Human Exposure to Ambient Polycyclic Aromatic-Hydrocarbons in a Coal-Burning Environment. Science of the Total Environment 92: 145-154.

73. Archibong AE, Inyang F, Ramesh A, Greenwood M, Nayyar T, et al. (2002) Alteration of pregnancy related hormones and fetal survival in F-344 rats exposed by inhalation to benzo(a)pyrene. Reprod Toxicol 16: 801-808.

74. Bui QQ Tran MB, West WL (1986) A comparative study of the reproductive effects of methadone and benzo(a)pyrene in the pregnant and pseudopregnant rat. Toxicology 42: 195-204.

75. Takeda K, Tsukue N, Yoshida S (2004) Endocrine-disrupting activity of chemicals in diesel exhaust and diesel exhaust particles. Environ Sci 11: 33-45.

76. Dejmek J, Solansky I, Benes I, Lenicek J, Sram RJ (2000) The impact of polycyclic aromatic hydrocarbons and fine particles on pregnancy outcome. Environ Health Perspect 108: 1159-1164.

77. Manchester DK, Gordon SK, Golas CL, Roberts EA, Okey AB (1987) Ah receptor in human placenta: stabilization by molybdate and characterization of binding of 2,3,7,8-tetrachlorodibenzo-p-dioxin, 3-methylcholanthrene, and benzo(a)pyrene. Cancer Res 47: 4861-4868.

78. Meyn MS (1995) Ataxia-telangiectasia and cellular responses to DNA damage. Cancer Res 55: 5991-6001

79. Nicol CJ, Harrison ML, Laposa RR, Gimelshtein IL, Wells PG (1995) A teratologic suppressor role for p53 in benzo[a]pyrene-treated transgenic p53deficient mice. Nat Genet 10: 181-187.

80. Wood KA, Youle RJ (1995) The role of free radicals and p53 in neuron apoptosis in vivo. J Neuroscience 15: 5851-5857. 
81. Saunders CR, Das SK, Ramesh A, Shockley DC, Mukherjee S (2006) Benzo(a)pyrene-induced acute neurotoxicity in the F-344 rat: role of oxidative stress. J Appl Toxicol 26: 427-438.

82. Wilson VL, Jones PA (1983) Inhibition of DNA methylation by chemical carcinogens in vitro. Cell 32: 239-246.

83. Stiles J, Jernigan TL (2010) The basics of brain development. Neuropsychol Rev 20: $327-348$.

84. Garzon DL, Huang H, Todd RD (2008) Do Attention Deficit/Hyperactivity Disorder and Oppositional Defiant Disorder Influence Preschool Unintentional Injury Risk? Archives of Psychiatric Nursing 22: 288-296.
85. Wood JJ (2006) Effect of anxiety reduction on children's school performance and social adjustment. Dev Psychol 42: 345-349.

86. Knapp M, King D, Healey A, Thomass C (2011) Economic Outcomes in Adulthood and their Associations with Antisocial Conduct, Attention Deficit and Anxiety Problems in Childhood. Journal of Mental Health Policy and Economics 14: 137-147.

87. Kotsopoulos N, Connolly MP, Sobanski E, Postma MJ (2013) The fiscal consequences of ADHD in Germany: a quantitative analysis based on differences in educational attainment and lifetime earnings. J Ment Health Policy Econ 16: 27-33. 